\title{
Age-structured genetic analysis reveals temporal and geographic variation within and between two cryptic rockfish species
}

\author{
Martha O. Burford ${ }^{1,2, *}$, Mark H. Carr ${ }^{1}$, Giacomo Bernardi ${ }^{1}$ \\ ${ }^{1}$ Department of Ecology and Evolutionary Biology, University of California Santa Cruz, 100 Shaffer Road, Santa Cruz, \\ California 95060, USA \\ ${ }^{2}$ Present address: Department of Biology, University of Central Oklahoma, 100 North University Drive, Edmond, \\ Oklahoma 73034, USA
}

\begin{abstract}
The spatial patterns of genetic structure among juveniles of long-lived species can reveal the extent of interannual and geographic variation in realized larval dispersal as well as the processes that determine ecologically relevant patterns of population connectivity. However, few studies examine this temporal and spatial variation over large portions of a species' geographic range or between cryptic species that overlap in their range. Despite the potential for long-distance dispersal in blue rockfish Sebastes mystinus, a previous study of adults revealed two geographically distinct, cryptic species. To determine year-to-year variation in the patterns of spatial connectivity and to elucidate the potential ecological mechanisms involved in shaping new yearclasses and maintaining cryptic species, we sampled juveniles within California, USA, where both cryptic species coexist. Using microsatellite markers, we found geographic and temporal variation in the number of individuals from these distinct cryptic species within 2 new year-classes of juvenile $S$. mystinus. We also found differences in the geographic patterns of genetic structure of the 2 cryptic species. Whereas one species exhibited little or no spatial genetic structure across the study region, the other exhibited a complex geographic pattern of genetic structure, with little or no genetic structure among regions, but small-scale structure within a region. The results of this study demonstrate that the spatial scales and patterns of realized dispersal of pelagic larvae vary geographically, interannually, and between closely related species with similar life-history strategies. Therefore, estimates of dispersal based on larval duration and patterns of adult structure need to be interpreted cautiously.
\end{abstract}

KEY WORDS: Cryptic species - Range expansion - Ecological genetics · Local adaptation · Sebastes spp.

\section{INTRODUCTION}

Life histories of many marine species are 'bipartite;' adults are relatively sedentary, but larvae have pelagic durations of several weeks to months, with potential for dispersal over large distances across a species' range. This dispersal and the difficulty in tracking early life stages pose several challenges, ranging from small to larger spatial and temporal scales, for assessing connectivity and gene flow among populations. Moreover, the ability to predict the ecology and evolutionary trajectory of marine species depends on correct assessment of the amount of realized dispersal between populations (Cowen et al. 2007, Cowen $\&$ Sponaugle 2009). The duration of the pelagic larval phase of marine organisms is thought to be indicative 
of dispersal ability, rates of gene flow, and the spatial extent of genetic homogeneity of populations. Patterns of the genetic structure of adults are often assumed to reflect realized patterns of larval dispersal (e.g. Waples 1987), though the spatial and temporal variability of this relationship is rarely assessed and poorly understood (Palumbi 2003). To increase our understanding of the spatial and temporal variation in this relationship, it is critical to assess the genetic signature of populations throughout the geographic range (spatial variation) and over multiple years or different stages (e.g. adults, juveniles, or larvae; temporal variation). These genetic assessments will increase our understanding of how estimates of pelagic duration relate to realized patterns of dispersal. In addition, while the genetic assessment of adults in these populations provides information on effective dispersal in the past (i.e. individuals that disperse, survive, and reproduce), an analysis of yearclasses of offspring provides a direct measure of current realized dispersal and connectivity. In long-lived species, the genetic structure of the reproductive population integrates many year-classes produced under a variety of environmental conditions. While comparison of the geographic patterns of genetic structure of individual year-classes may reflect the effects of evolutionary events (e.g. geographic variation in hybridization between species; Burford et al. 2011), it also provides information on contemporary events that may limit or promote variation in reproductive success and dispersal of offspring. Such an analysis can identify factors that influence the formation of new year-classes via reproductive success and dispersal, identify the degree of year-to-year variation in these factors, and may possibly explain how these factors influence speciation events.

Rockfishes (Sebastes spp.) are a species-rich genus of long-lived fish that span large geographic areas and vary in key life-history characteristics, such as pelagic larval duration (Love et al. 2002). Therefore large-scale genetic analyses of species within this group provide an opportunity to investigate the genetic consequences of dispersal for species with multiple year-classes and, potentially, different levels of connectivity. For this reason and because of their great economic and ecological importance along the west coast of North America, the genus Sebastes has received much attention, with development of genetic markers and previous descriptions of the spatial genetic structure of several species (Buonaccorsi et al. 2002, 2004, Miller et al. 2005, Burford \& Bernardi 2008, Hyde et al. 2008, Burford 2009, Sivasundar \& Palumbi 2010, Hess et al. 2011). Due to the longevity of some species in this group, rockfishes provide an opportunity to examine how genetic variation among year-classes and the different environmental conditions they experience contribute to the genetic variation of local and regional adult populations. Understanding the association between genetic structure and ecological conditions will contribute to a better understanding of connectivity and recruitment dynamics of marine species (e.g. Selkoe et al. 2008).

Here, we investigate the degree of spatial and temporal genetic variation among new year-classes in a widespread, coastal marine fish, the blue rockfish Sebastes mystinus, which settles in temperate rocky reef habitats from northern Baja California, Mexico, to Vancouver Island, British Columbia, and we compare these new year-classes to the adult population. Like many rockfishes, $S$. mystinus are long-lived $(\sim 45 \mathrm{yr})$, reproductive at $\sim 5 \mathrm{yr}$ of age and relatively sedentary as adults, but posses an extended pelagic phase ( $\sim$ to $5 \mathrm{mo}$; Love et al. 2002). The long pelagic phase of $S$. mystinus creates the potential for extensive larval dispersal, which predicts genetic homogeneity over large geographic distances (Burford \& Larson 2007). However, there is evidence of recent cryptic speciation within $S$. mystinus (mean $\pm \mathrm{SD}$ : $\sim 520 \pm 115 \mathrm{kyr}$; Burford 2009) across its geographic range (southern California to northern Washington). The 2 species were reproductively isolated and have a north-south distribution pattern, with a northerly and southerly distributed Type 1 and Type 2 species, respectively (Burford \& Bernardi 2008, Burford 2009), and a range of overlap from central/southern Oregon to northern California ( 450 km; Burford 2009). In an analysis of hybridization of settling $S$. mystinus juveniles, there was little or no evidence of first generation hybrids, suggesting that reproductive isolation between the 2 species in regions where both coexist was due to pre-zygotic barriers (Burford et al. 2011). Within the adult populations of each species there was evidence of genetic differentiation only in the southerly-distributed species at 2 locations (Santa Rosa Island and Gaviota, both south of Point Conception), suggesting that while the long pelagic phase contributed to connectivity in the northerly-distributed species, the same was not true for the southerlydistributed species (Burford 2009).

Currently it is unknown whether both species have exactly the same life history traits. However, due to the similar life history traits of other members of the subgenus Sebastosomus, which Sebastes mystinus belongs to (Love et al. 2002, Hyde \& Vetter 2007), both species likely share a long pelagic duration and age of first reproduction. With the geographic struc- 
ture and the reproductive isolation between these 2 closely related species, an analysis of the genetic structure of juveniles and adults provides an opportunity to assess relationships between the genetic composition of adults and new year-classes. In addition, the genetic analysis provides information on temporal and spatial variation in processes that influence the formation of new year-classes within a species, and between recently derived species. Given the close phylogenetic relationship between the 2 cryptic species of $S$. mystinus, comparison of genetic structure within species will further the understanding of any variation in the link between potential and realized dispersal.

To understand the variation in processes that influence new year-classes, we focused on 2 aspects: the species composition of new year-classes and the genetic structure within species. We addressed these aspects by assessing the temporal and spatial variation of new year-classes through (1) comparing the species composition between new year-classes, (2) comparing individual year-classes to regional and local adults to understand the consistency of species composition, and (3) analyzing within species genetic structure to assess the degree of genetic differentiation within or between individual year-classes. The relationship of the species composition of individual year-classes at a given settlement location may change over time, indicating either stochastic variation in recruitment strength or a change in frequency of the 2 cryptic species. The comparisons within and between new year-classes focus on shorter time-scales. The comparisons between juveniles and adults, which contain individuals born at least 5 yr prior to these new year-classes, provide a degree of variation over longer time scales, from settling juveniles to reproductive adults. Therefore, with the age-structured method we can quantify the degree of temporal consistency of any observed genetic patterns of a new year-class of both species and help clarify how population dynamics and evolutionary forces act on the species (Ruzzante et al. 1997).

The information gained from this type of study is important to the management of fished populations, to first confirm any temporal or spatial differences in species composition and then to identify factors that may influence these differences. In addition, understanding genetic variation within species will identify regions with lower genetic diversity or lower effective population sizes, and will help determine where species need to be conserved within their respective ranges.

\section{MATERIALS AND METHODS}

\section{Sampling}

We designed the sampling of new year-classes to incorporate several spatial scales (within and among regions) covering $\sim 680 \mathrm{~km}$ of the species' range within California (northern Channel Island to Fort Bragg) and 2 temporal comparisons, between new year-classes and between new year-classes and adults, which are comprised of older year-classes. We compared 3 consecutive year-classes, 2 year-classes throughout the sampling region (2001 and 2002) and a limited sample of the 2000 year-class from a previous study (Burford \& Larson 2007), and we compared these individual year-classes to regional and local adults from a previous study (Burford 2009) (Appendix 1). Given that most Sebastes mystinus become reproductive around the age of $5 \mathrm{yr}$, these adults were comprised of older year-classes than the juveniles sampled here, as most of the collections of adults occurred at the same time or shortly after the collections of juveniles (e.g. 2002 and 2003), with the exception of the sample at Fort Bragg. At this location, collections of adults occurred in 2006, which likely included adults from the 2000, 2001, and 2002 year-classes.

We sampled juveniles from locations within and outside areas where both cryptic species of Sebastes mystinus (Type 1 and Type 2) co-occur, along $680 \mathrm{~km}$ of coast between southern California (Santa Barbara: $\left.34^{\circ} 25^{\prime} 52.98 " \mathrm{~N}, 119^{\circ} 56^{\prime} 8.50^{\prime \prime} \mathrm{W}\right)$ and northern California (Fort Bragg: $39^{\circ} 25^{\prime} 48.77^{\prime \prime} \mathrm{N}, 123^{\circ} 48^{\prime} 49.99^{\prime \prime} \mathrm{W}$ ). Within this region, upwelling and relaxation events may influence the settlement patterns of marine organisms with pelagic larvae such as rockfishes (Roughgarden et al. 1991, Larson et al. 1994, Wing et al. 1995a, 1995b, Caselle et al. 2010). We designated regions (north, central, and southern) because major upwelling zones and/or biogeographic boundaries divide these regions (Fig. 1; e.g. Point Reyes, Wing et al. 1995a; Point Conception, Wares et al. 2001), and a previous study using microsatellite loci found small-scale genetic structure within the Type 2 species between adults sampled south of Point Conception with those to the north of Point Conception (Burford 2009). As different upwelling centers may have inherently different long-term influences on recruitment patterns, we organized the sampling locations to include at least 2 locations between upwelling centers (Fig. 1). The sample locations also include regions where both genetic species of adults coexist and regions where one of the 2 species predominates. 


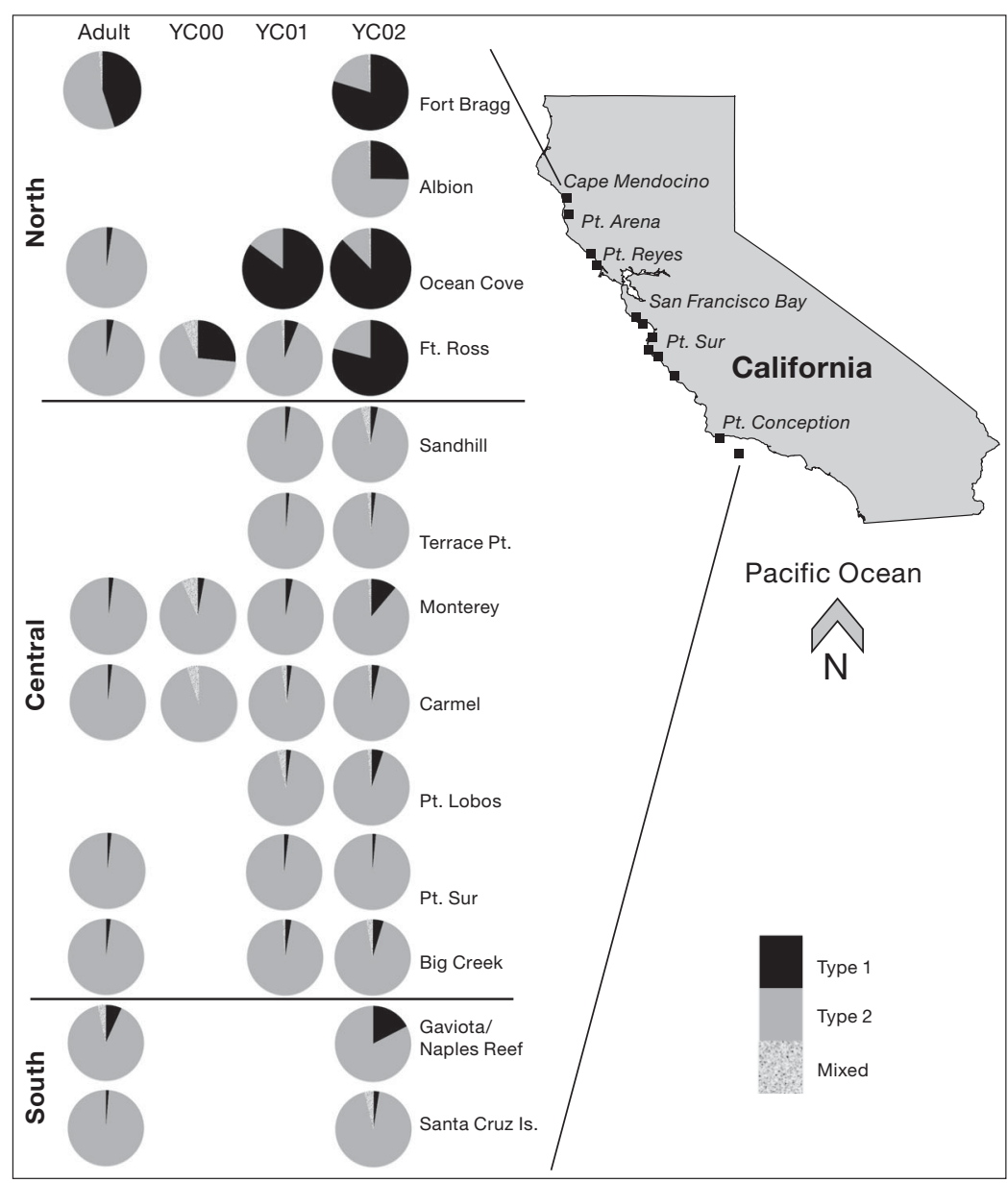

Fig. 1. Sebastes mystinus. Distribution of sample locations and genetic structure of adults and juveniles. Geographic features are identified in italics. Pie charts are the summary of the STRUCTURE assignment using microsatellite loci, and from left to right represent individuals from the adult year-classes, and juveniles from the 2000 (Burford \& Larson 2007), 2001 and 2002 year-classes (YC00, YC01 and YC02, respectively). Type 1, Type 2 and Mixed (admixed individuals) refer to microsatellite-defined groups. The sampling range within California is divided into 3 regions, north, central, and south, which are depicted on the left-hand side of the figure

We sampled, on average, 100 juveniles from each sampling location in 2001 and in 2002 (Table 1). To collect a diverse sample of sizes of juveniles, we used SCUBA and a large underwater hand-held, $4.8 \mathrm{~mm}$ square mesh BINCKE net (Anderson \& Carr 1998, Ammann 2004). We sampled the majority of sites within a few days in each year. Exceptions to this were collections made several weeks later in the season, at Fort Ross and Ocean Cove in 2001 and Santa Cruz Island and Naples Reef in 2002. We froze whole individuals from each site for later processing, which included positive identification using diagnostics (e.g. coloration, dorsal fin ray counts, and gill raker counts; Miller \& Lea 1972, Laroche \& Richardson 1981), measuring standard lengths, and then preserv- ing whole individuals in $95 \%$ ethanol for subsequent genetic analyses. For a subset of adult sampling locations (Ocean Cove, Monterey, Avila, and Santa Cruz Island), Gundelfinger (2005) used otolith microstructure to analyze the age-structure of the same adults we sampled genetically. We reference these data to show the age composition of the sample of adults and to confirm temporal differences between juveniles and adults at these specific sample locations.

\section{DNA extraction and amplification}

For the microsatellite analysis, we extracted genomic DNA from the caudal fin of each specimen using a Qiagen DNA extraction kit (Qiagen) and following the manufacturer's protocol. From the extracted genomic DNA, we amplified 6 microsatellite loci designed from Sebastes rastrelliger (Sra.7-2, Sra.7-7, Sra.7-25, Sra.6-52, Sra.15-8, Sra.16-5, GenBank Accession numbers: AF26905457, AF269059, AF269061, respectively; Buonaccorsi et al. 2004, Westerman et al. 2005), using polymerase chain reaction (PCR). We followed the protocol outlined in Burford \& Larson (2007) and Burford \& Bernardi (2008) for fragment amplification and scoring of these 6 microsatellite loci. In total, we analyzed 760 individuals from 9 locations for the 2001 year-class and 1478 individuals from 13 locations for the 2002 year-class (Fig. 1, Table 1).

\section{Microsatellite loci analysis}

General microsatellite analysis of Sebastes mystinus collections for each cryptic species included: (1) an estimate of genetic diversity (Nei 1987) and allelic richness (at equivalent sample sizes) using FSTAT version 2.9.3.2 (Goudet 1995), (2) an estimate of expected and observed heterozygosity $\left(H_{\mathrm{e}}\right.$ and $H_{\mathrm{o}}$ ) using ARLEQUIN 2.000, and (3) deviations from Hardy-Weinberg (HW) genotypic expectations and independence of microsatellite loci (linkage equilib- 
Table 1. Sebastes mystinus. Sample data and summary statistics of juveniles, including sample location, sample date, sample size (N), mean standard length (SL), allele number (no.), allelic richness (A), observed $\left(H_{\mathrm{o}}\right)$ and expected $\left(H_{\mathrm{e}}\right)$ heterozygosity, p-values for Hardy-Weinberg (HW) and Linkage equilibrium (LE) violations (NS = not significant, ${ }^{*} \mathrm{p}<0.05$; implemented in GENEPOP using 10000 iterations). Bolded locations were collected within days of each other and non-bolded locations were sampled at dates later in the season. Allelic richness measures based on 60 and 24 diploid individuals for the 2001 and 2002 sample locations, respectively, and 439 diploid individuals for types. NA = not applicable

\begin{tabular}{|c|c|c|c|c|c|c|c|c|c|c|}
\hline Year & Location & Collection date & $\mathrm{N}$ & $\mathrm{SL}(\mathrm{mm})$ & Allele no. & A & $H_{\mathrm{o}}$ & $H_{\mathrm{e}}$ & HW & LE \\
\hline \multirow[t]{9}{*}{2001} & Ocean Cv. & 23 Aug & 84 & 63.27 & 17.17 & 15.86 & 0.74 & 0.81 & $*$ & NS \\
\hline & Ft. Ross & $22 \mathrm{Aug}$ & 78 & 63.55 & 15.33 & 14.53 & 0.80 & 0.81 & NS & NS \\
\hline & Sandhill & $10 \mathrm{Jul}$ & 72 & 52.47 & 15.50 & 14.84 & 0.79 & 0.80 & NS & NS \\
\hline & Terrace Pt. & $10 \mathrm{Jul}$ & 89 & 54.87 & 16.50 & 15.07 & 0.76 & 0.78 & NS & NS \\
\hline & Monterey & $16 \mathrm{Jul}$ & 61 & 59.40 & 14.00 & 13.98 & 0.75 & 0.81 & NS & NS \\
\hline & Carmel & $16 \mathrm{Jul}$ & 93 & 55.10 & 16.17 & 14.68 & 0.75 & 0.80 & NS & NS \\
\hline & Pt. Lobos & $11 \mathrm{Jul}$ & 109 & 51.24 & 17.83 & 15.43 & 0.80 & 0.80 & NS & NS \\
\hline & Pt. Sur & $12 \mathrm{Jul}$ & 75 & 53.04 & 15.17 & 14.40 & 0.78 & 0.79 & NS & NS \\
\hline & Big Creek & $11 \mathrm{Jul}$ & 99 & 54.11 & 16.17 & 14.44 & 0.77 & 0.79 & NS & NS \\
\hline \multirow[t]{13}{*}{2002} & Ft. Bragg & $1 \mathrm{Aug}$ & 116 & 54.16 & 18.50 & 11.86 & 0.77 & 0.82 & * & NS \\
\hline & Albion & $1 \mathrm{Aug}$ & 133 & 51.62 & 20.17 & 12.52 & 0.78 & 0.83 & * & NS \\
\hline & Ocean Cv. & $31 \mathrm{Jul}$ & 147 & 54.16 & 20.67 & 12.43 & 0.76 & 0.81 & * & NS \\
\hline & Ft. Ross & $31 \mathrm{Jul}$ & 129 & 54.66 & 20.67 & 12.55 & 0.76 & 0.83 & $*$ & NS \\
\hline & Sandhill & $24 \mathrm{Jul}$ & 97 & 54.50 & 17.67 & 11.27 & 0.77 & 0.78 & NS & NS \\
\hline & Terrace Pt. & $24 \mathrm{Jul}$ & 128 & 55.04 & 18.67 & 11.38 & 0.78 & 0.79 & NS & NS \\
\hline & Monterey & $27 \mathrm{Jul}$ & 164 & 57.33 & 19.33 & 11.90 & 0.77 & 0.81 & $*$ & NS \\
\hline & Carmel & $27 \mathrm{Jul}$ & 132 & 59.89 & 18.67 & 11.50 & 0.79 & 0.80 & NS & NS \\
\hline & Pt. Lobos & $25 \mathrm{Jul}$ & 126 & 53.73 & 18.17 & 11.56 & 0.76 & 0.79 & $*$ & NS \\
\hline & Pt. Sur & $26 \mathrm{Jul}$ & 98 & 55.32 & 17.33 & 11.06 & 0.76 & 0.78 & NS & NS \\
\hline & Big Creek & $25 \mathrm{Jul}$ & 125 & 55.68 & 19.83 & 11.78 & 0.78 & 0.81 & ${ }^{*}$ & NS \\
\hline & Santa Cruz Is. & 13 Aug & 26 & 70.47 & 10.67 & 10.50 & 0.78 & 0.80 & NS & NS \\
\hline & Naples Reef & 28 Aug & 57 & 73.55 & 16.67 & 12.47 & 0.80 & 0.83 & NS & NS \\
\hline \multirow[t]{2}{*}{$2001 / 2002$} & Tyре 1 & NA & 466 & NA & 21.83 & 21.74 & 0.77 & 0.79 & NS & NS \\
\hline & Type 2 & NA & 1752 & NA & 28.17 & 23.17 & 0.77 & 0.79 & ${ }^{*}$ & NS \\
\hline
\end{tabular}

rium) using an exact test (Guo \& Thompson 1992) as implemented in GENEPOP version 3.2 (Raymond \& Rousset 1995a). For all exact tests, we generated significance probabilities using the Markov chain method as described in Guo \& Thompson (1992) using 10000 iterations; we used a sequential Bonferonni (Rice 1989) to correct for multiple comparisons and to avoid Type 1 error, and Fisher's method of combining probabilities (Raymond \& Rousset 1995a, 1995b, Sokal \& Rohlf 1995). For comparisons of diversity measures, we used a two-tailed or one-tailed, paired $t$-test (Sokal \& Rohlf 1995) to test for lower genetic diversity among juvenile and between juvenile samples and adult samples, respectively.

\section{Spatial and temporal analysis of genetic structure}

We analyzed the overall genetic structure for the juvenile samples within species using $F$-statistics, including unbiased estimates of $F_{\mathrm{ST}}$ and $F_{\mathrm{IS}}$ (Weir \&
Cockerham 1984) and pairwise differences of $F_{\text {ST }}$ values in FSTAT using 10000 permutations to generate p-values.

We conducted both spatial (between and within regions) and temporal (between year-classes and between year-classes and adults) analyses assessing both species composition and within species structure. We also analyzed differences in genetic diversity within species, comparing each species to the respective adult sample to test for a decrease in genetic diversity predicted by Hedgecock's sweepstakes hypothesis (Hedgecock et al. 1994. For this test, we compared (a) individual juvenile samples to the nearest adult site and (b) individual juvenile samples to adults pooled within a region (northern, central, and southern). Within the central region, we also compared juveniles to pooled adults from more restricted regions: the Monterey Peninsula, which included Monterey and Carmel adults, and the Big Sur region, which included Point Sur and Big Creek adults. 


\section{Individual assignment and geographic cluster analysis}

To test the geographic clustering of genotypes among individual juvenile sample locations, we conducted a Bayesian assignment test in STRUCTURE (Pritchard et al. 2000). We used this analysis to fit the structure of the juvenile samples to an appropriate number of clusters or groups $(K)$ by using several grouping priors $(K)$, an admixture model, and allowing correlation among allele frequencies (Falush et al. 2003). We ran all juveniles from both year-classes and all adults together and generated posterior probabilities in STRUCTURE using 100000 iterations of the Markov chain Monte Carlo (MCMC) method after an initial burn-in period of 40000 iterations. We averaged the posterior probabilities for each individual over the 5 runs and, in contrast to previous analyses (Burford \& Bernardi 2008, Burford 2009), we assigned individuals with a posterior probability assignment of 0.75 or greater to one of the 2 species (following Burford et al. 2011). We verified $K$ and the stability of other model parameters by running the model with 5 replicates and $\Delta K$-values ranging from 1 to 5 and analyzing the log-likelihood, the data estimate $[\ln (\operatorname{Pr}(\mathrm{X} / K))]$, and variance structure of the estimated log (natural) probability for different $K \mathrm{~s}$ (Appendix 2). We confirmed $K$ by using a post-hoc analysis of $\Delta K$ following Evanno et al. (2005). We calculated final posterior probabilities using all 5 runs (Appendix 3).

To further test the clustering of genotypes and to visualize and confirm patterns observed in assignment tests, we conducted a principal component analysis (PCA) on multilocus genotypes using 10000 randomizations as implemented in PCAGEN version 1.2 (Goudet 1999). We conducted 2 PCAs, including a comparison of all locations and locations divided among species (Type 1 and Type 2) combining both year-classes.

\section{RESULTS}

\section{Age structure}

At the 4 sampling locations anlayzed, there were a range of ages represented in the adult population, with some years not represented or under-represented in the adults. This variation in age composition demonstrated that reproductive adults were born in different years, and potentially in different environmental conditions from each other. At the 4 sampling locations where Gundelfinger (2005) determined age-structure of the adult populations (from north to south: Ocean Cove, Monterey, Avila and Santa Cruz Island), we analyzed all but the individuals that were born in 1999 because they were not of reproductive age at the time of the collection. Age classes of adults ranged from 1978 to 1998 at Ocean Cove; 1982 to 1998 at Monterey and Avila; and the 1998 year-class exclusively at Santa Cruz Island. The dominant age class of adults varied among the 4 sites: 1995, 1995, 1991 and 1998 at Ocean Cove, Monterey, Avila and Santa Cruz Island, respectively. There were also high frequencies of the 1987 year-class at Ocean Cove, Monterey, and Avila, and the 1991 and 1997, and 1995 year-classes at Monterey and Avila, respectively. Age classes were missing at some sites, including 1981 and 1983 at Ocean Cove, 1983 and 1884 at Monterey, 1983 at Avila, and all but the 1998 year-class at Santa Cruz Island.

\section{Microsatellite characteristics}

While we found a few sampling locations where genotype frequencies (all loci combined) violated HW expectation and linkage equilibrium significantly, genotype frequencies conformed to both HW expectation and Linkage equilibrium when we analyzed the 2 species separately at most locations (Table 1). The one exception was the Type 1 species at Ocean Cove in 2002, which remained out of HW equilibrium. There were no significant differences in genetic diversity for all measures among juvenile sites from both year-classes or among samples within the 2 species (paired $t$-test, $\mathrm{p}>0.05$ ).

\section{Spatial pattern of genetic structure in juvenile year-classes}

Between species. The results of the structured analysis showed there was a higher frequency of Type 1 individuals in the northern part of the distribution than in the central and southern regions and a higher frequency of Type 2 individuals in the central and southern regions, and this was consistent over both years with a few exceptions. In the 2001 yearclass, there was a marked decrease (86 to $4 \%$ ) in the Type 1 species in the northern region, just south of Ocean Cove at Fort Ross $(6 \mathrm{~km}$ south of Ocean Cove; Fig. 1, Table 2). The Type 1 species remained at a low frequency ( 0 to $4 \%$ ) throughout the central and southern regions. Similar to the 2001 year-class, 
Table 2. Sebastes mystinus. Results of the STRUCTURE admixture assignment of juveniles and adults using microsatellite loci and $K=2$. The table includes the sample size $(\mathrm{N})$ and posterior probabilities for assignment to each group (Type 1 and Type 2) for each location

\begin{tabular}{|c|c|c|c|c|}
\hline \multirow[t]{2}{*}{ Location } & \multirow[t]{2}{*}{$\mathrm{N}$} & \multicolumn{3}{|c|}{ — Frequency } \\
\hline & & Type 1 & Type 2 & Mixed \\
\hline \multicolumn{5}{|c|}{2001 Year-Class } \\
\hline Ocean Cove & 84 & 0.852 & 0.148 & \\
\hline Ft. Ross & 78 & 0.060 & 0.927 & 0.013 \\
\hline Sandhill & 72 & 0.023 & 0.977 & \\
\hline Terrace Pt. & 89 & 0.015 & 0.985 & \\
\hline Monterey & 61 & 0.031 & 0.969 & \\
\hline Carmel & 93 & 0.022 & 0.956 & 0.022 \\
\hline Pt. Lobos & 109 & 0.022 & 0.941 & 0.037 \\
\hline Pt. Sur & 75 & 0.020 & 0.980 & \\
\hline Big Creek & 99 & 0.027 & 0.963 & 0.010 \\
\hline \multicolumn{5}{|c|}{2002 Year-Class } \\
\hline Ft. Bragg & 116 & 0.798 & 0.193 & 0.009 \\
\hline Albion & 133 & 0.252 & 0.740 & 0.008 \\
\hline Ocean Cove & 147 & 0.881 & 0.116 & 0.007 \\
\hline Ft. Ross & 129 & 0.791 & 0.209 & \\
\hline Sandhill & 97 & 0.034 & 0.966 & 0.041 \\
\hline Terrace Pt. & 128 & 0.020 & 0.964 & 0.016 \\
\hline Monterey & 164 & 0.111 & 0.877 & 0.012 \\
\hline Carmel & 132 & 0.034 & 0.951 & 0.015 \\
\hline Pt. Lobos & 126 & 0.051 & 0.933 & 0.016 \\
\hline Pt. Sur & 98 & 0.016 & 0.984 & \\
\hline Big Creek & 125 & 0.047 & 0.927 & 0.026 \\
\hline Naples Reef & 57 & 0.174 & 0.826 & \\
\hline Santa Cruz Is. & 26 & 0.025 & 0.937 & 0.038 \\
\hline Total/Avg. & 2238 & 0.196 & 0.794 & 0.019 \\
\hline \multicolumn{5}{|l|}{ Adults $^{\mathrm{a}}$} \\
\hline Ft. Bragg & 66 & 0.450 & 0.535 & 0.015 \\
\hline Ocean Cove & 41 & 0.024 & 0.976 & \\
\hline Ft. Ross & 60 & 0.031 & 0.969 & \\
\hline Monterey & 47 & 0.021 & 0.979 & \\
\hline Carmel & 86 & 0.019 & 0.981 & \\
\hline Pt. Sur & 52 & 0.018 & 0.982 & \\
\hline Big Creek & 56 & 0.020 & 0.980 & \\
\hline Gaviota & 59 & 0.068 & 0.898 & 0.034 \\
\hline Santa Cruz Is. & 15 & 0.013 & 0.987 & \\
\hline
\end{tabular}

there was a higher frequency of Type 1 individuals in the north $(\sim 83 \%)$ and a markedly lower frequency to the south $(\sim 3 \%)$ for the 2002 year-class. However, we found the decrease in the number of Type 1 individuals in the 2002 year-class was slightly further south than found in the 2001 year-class (Fig. 1, Table 2). In addition, the northern region had higher frequencies of Type 2 individuals at Albion (78\%), Fort Bragg $(16 \%)$ and Fort Ross $(17 \%)$, and higher numbers of Type 1 individuals in central and southern samples (Monterey 9\%, Naples Reef 16\%, respectively) than other locations in either region.
The PCA showed clear discrimination between the 2 cryptic species (Type 1 and Type 2, Fig. 2) and confirmed significant patterns observed in the pairwise $F_{\mathrm{ST}}$ analysis $(\mathrm{p}<0.05$, between Type 1 and Type 2, $F_{\mathrm{ST}}=0.12$ in 2001, $F_{S T}=0.12$ in 2002). Specifically, PC1 explained $85 \%$ of the variation between samples and clearly separated the 2 species. PC2, which was not significant, showed spread among samples within species.

Within species. We found reduced genetic distinctiveness within species compared to that found between the 2 species. For example, the samples of Type 1 and Type 2 individuals at Naples Reef were similar to all other samples of the respective species in the sampling range (Table $3 a, b)$. However, within the Type 2 species, we found low but significant genetic differentiation within the central region in both year-classes (Table 3b). Specifically, the Type 2 samples at Monterey differed significantly from other locations in the central region (Sandhill, Terrace Point, and Point Sur) in 2001, and Sandhill differed significantly from Point Lobos in the central region in 2002. We found no other geographic differences within the Type 2 species. While the PC2 showed greater genetic variance in the Type 2 species and a difference between the 2 locations in the central/southern region and locations in the northern region in the Type 1 species (Fig. 2), it was not significant.

\section{Temporal patterns of species composition in juvenile year-classes}

Between year-classes. Differences in the proportionate composition of the 2 species caused significant genetic differences between the 2 year-classes when we compared sampling locations from both years (Fig. 1, Table 2). This was due to an increase in frequency of the Type 1 species between years. In the northern region, this included an increase of Type 1 juveniles between 2001 and 2002 from 85 to $88 \%$ and from 6 to $80 \%$ at Ocean Cove and Fort Ross, respectively. Several locations in the central region also showed an increase in the frequency of Type 1 juveniles between the 2 years. For instance, individuals sampled in Monterey showed an increase in the Type 1 species between year-classes from 3 to $11 \%$.

Between juveniles and adults. The proportionate composition of different species in the adult and juvenile samples was similar, especially in the central region (Fig. 1, Table 2). However, in general we found a higher number of Type 1 individuals (Table 2) in the juvenile than in the adult sample, 
with the exception of the juvenile sample in Albion. In some cases, this difference was substantial. In the 2002 year-class, the juvenile samples in 3 northern sample locations and had higher proportions of the Type 1 species than the respective adult samples (80 vs. $45 \%$ at Fort Bragg; 88 vs. $2 \%$ at Ocean Cove; and 79 vs. $3 \%$ at Fort Ross). This was also true for the 2 previous year-classes (2000 and 2001) at Fort Ross and the 2001 sample at Ocean Cove. We also found, to a lesser degree, a greater frequency of Type 1 juveniles within the central region at a few of the 2002 year-class sample locations compared to the adult samples at those locations (11 vs. $2 \%$ at Monterey and 17 vs. $7 \%$ at Naples Reef). However, the 2001 juvenile sample at Monterey had a similar percentage of Type 1 individuals to adults. Therefore, while the discrepancy in the proportion of Type 1 juveniles relative to adults was consistent over both years in both regions, it was greater in the north compared to the central/south and greater in the 2002 compared to the 2001 year-class. Genetic diversity in juvenile samples was not significantly lower than in adult

Table 3. Sebastes mystinus. Pairwise $F_{\mathrm{ST}}$ values of juveniles using microsatellite data, including pairwise comparisons of all locations in both year-classes divided into (a) Type 1 and (b) Type 2 species ( $\mathrm{N}=9$ or greater). Bolded numbers are significant after corrections for multiple comparisons using a sequential Bonferroni at an alpha level, ${ }^{*} \alpha=0.05$

\begin{tabular}{|c|c|c|c|c|c|c|c|}
\hline $\begin{array}{l}\text { (a) Type } 1 \\
\text { Population }\end{array}$ & OC01 & FB02 & AR02 & $\mathrm{OC} 02$ & FR02 & MB02 & NR02 \\
\hline \multicolumn{8}{|l|}{ Year-Classes } \\
\hline Ocean Cv. 2001 & - & & & & & & \\
\hline Ft. Bragg 2002 & 0.000 & - & & & & & \\
\hline Albion 2002 & 0.007 & 0.012 & - & & & & \\
\hline Ocean Cv. 2002 & 0.004 & 0.006 & 0.003 & - & & & \\
\hline Ft. Ross 2002 & 0.000 & 0.000 & 0.012 & 0.002 & - & & \\
\hline Monterey 2002 & 0.002 & $0.007^{*}$ & 0.021 & 0.011 & 0.005 & - & \\
\hline Naples Rf. 2002 & 0.000 & 0.000 & 0.014 & 0.006 & 0.000 & 0.001 & - \\
\hline
\end{tabular}

\begin{tabular}{|c|c|c|c|c|c|c|c|c|c|}
\hline $\begin{array}{l}\text { (b) Type } 2 \\
\text { Population }\end{array}$ & OC01 & FR01 & SH01 & ТP01 & MB01 & CB01 & PL01 & PS01 & ВC01 \\
\hline \multicolumn{10}{|c|}{2001 Year-Class } \\
\hline Ocean Cv. & - & & & & & & & & \\
\hline Ft. Ross & 0.000 & - & & & & & & & \\
\hline Sandhill & 0.000 & 0.002 & - & & & & & & \\
\hline Terrace Pt. & 0.000 & 0.002 & 0.002 & - & & & & & \\
\hline Monterey & 0.000 & 0.003 & $0.005^{*}$ & $0.006^{*}$ & - & & & & \\
\hline Carmel & 0.000 & 0.002 & 0.001 & 0.000 & 0.003 & - & & & \\
\hline Pt. Lobos & 0.000 & 0.001 & 0.001 & 0.001 & 0.001 & 0.000 & - & & \\
\hline Pt. Sur & 0.000 & 0.000 & 0.002 & 0.000 & $0.006^{*}$ & 0.000 & 0.001 & - & \\
\hline Big Creek & 0.000 & 0.001 & 0.001 & 0.001 & 0.000 & 0.002 & 0.001 & 0.000 & - \\
\hline Ft. Bragg & 0.000 & 0.000 & 0.000 & 0.003 & 0.002 & 0.000 & 0.000 & 0.002 & 0.003 \\
\hline \multicolumn{10}{|c|}{2002 Year-Class } \\
\hline Albion & 0.000 & 0.002 & 0.000 & 0.001 & $0.004^{*}$ & 0.000 & 0.000 & 0.003 & 0.001 \\
\hline Ocean Cv. & 0.000 & 0.003 & 0.000 & 0.000 & 0.007 & 0.000 & 0.000 & 0.005 & 0.005 \\
\hline Ft. Ross & 0.000 & 0.000 & 0.003 & 0.000 & 0.005 & 0.000 & 0.000 & 0.000 & 0.000 \\
\hline Sandhill & 0.000 & 0.001 & 0.003 & 0.000 & $0.005^{*}$ & 0.002 & 0.001 & 0.000 & 0.000 \\
\hline Terrace Pt. & 0.000 & 0.005 & 0.001 & 0.002 & $0^{0.003}{ }^{*}$ & 0.001 & 0.002 & 0.003 & 0.000 \\
\hline Monterey & 0.000 & 0.003 & 0.001 & 0.000 & 0.003 & 0.000 & 0.000 & 0.004 & 0.001 \\
\hline Carmel & 0.000 & 0.005 & 0.001 & 0.001 & 0.003 & 0.000 & 0.001 & 0.004 & 0.002 \\
\hline Pt. Lobos & 0.000 & 0.006 & 0.002 & 0.001 & 0.003 & 0.001 & 0.001 & 0.006 & 0.002 \\
\hline Pt. Sur & 0.000 & 0.002 & 0.001 & 0.000 & $0.004^{*}$ & 0.000 & 0.001 & 0.001 & 0.001 \\
\hline Big Creek & 0.000 & 0.003 & 0.001 & 0.002 & $0.002^{*}$ & 0.001 & 0.001 & 0.005 & 0.001 \\
\hline Santa Crz Is. & 0.000 & 0.005 & 0.005 & 0.004 & 0.000 & 0.000 & 0.000 & 0.006 & 0.000 \\
\hline Naples Rf & 0.000 & 0.000 & 0.000 & 0.001 & 0.000 & 0.000 & 0.000 & 0.002 & 0.000 \\
\hline
\end{tabular}




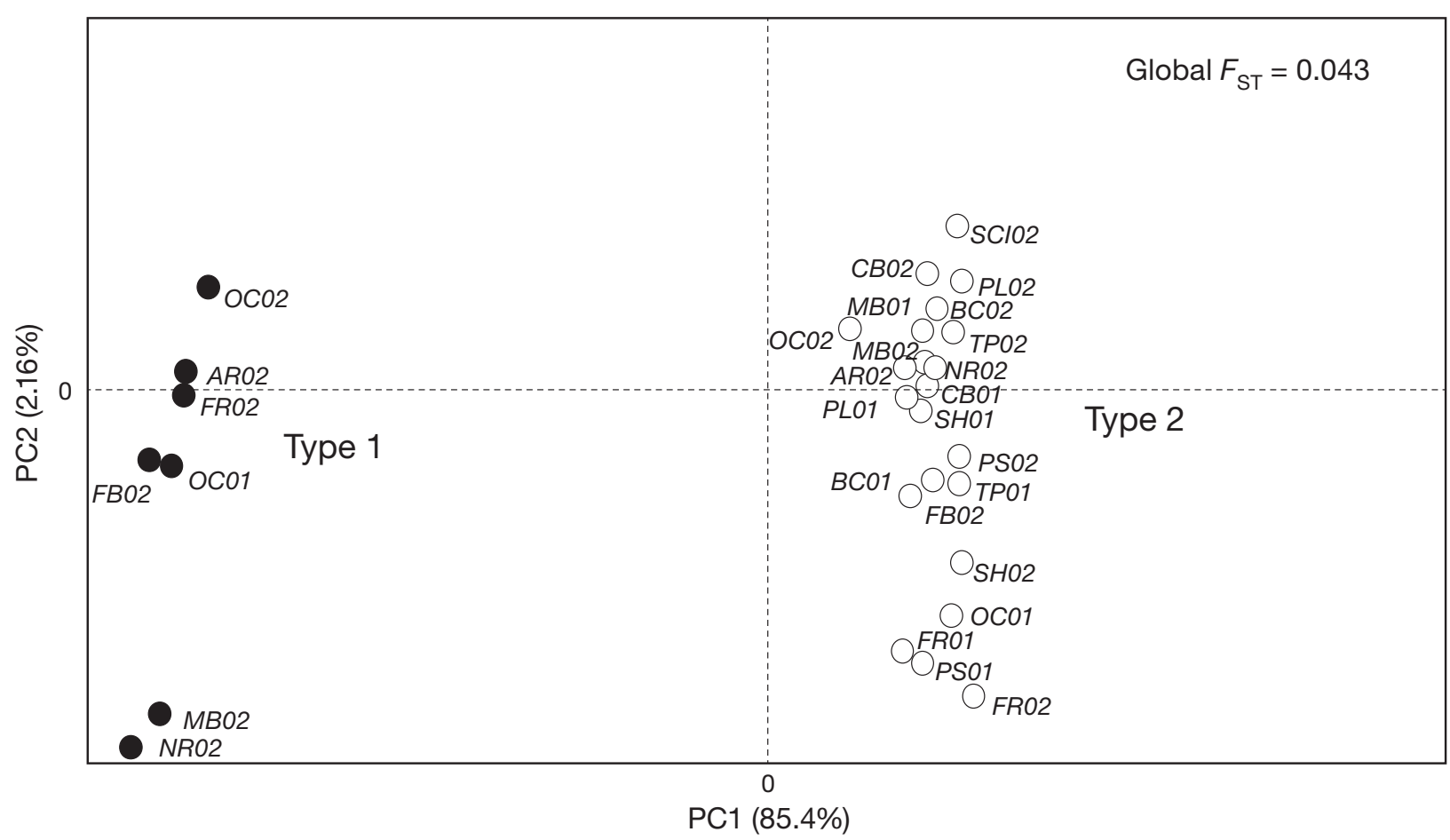

Fig. 2. Sebastes mystinus. Results of the PCA of juvenile samples using microsatellite data, including all sample locations with each location divided between Type 1 and Type 2. Location abbreviations are: Fort Bragg (FB), Albion (AR), Ocean Cove (OC), Fort Ross (FR), Sandhill (SH), Terrace Point (TP), Monterey (MB), Carmel (CB), Point Lobos (PL), Point Sur (PS), Big Creek (BC), Santa Cruz Island (SCI), Naples Reef (NR). '01' and '02' refer to year-classes 2001 and 2002, respectively

\begin{tabular}{|c|c|c|c|c|c|c|c|c|c|c|c|}
\hline 0.002 & - & & & & & & & & & & \\
\hline 0.000 & 0.000 & - & & & & & & & & & \\
\hline 0.006 & 0.001 & 0.007 & - & & & & & & & & \\
\hline 0.003 & 0.001 & 0.007 & 0.000 & - & & & & & & & \\
\hline 0.006 & 0.000 & 0.005 & 0.001 & 0.000 & - & & & & & & \\
\hline 0.003 & 0.000 & 0.000 & 0.001 & 0.002 & 0.000 & - & & & & & \\
\hline 0.001 & 0.000 & 0.000 & 0.004 & 0.003 & 0.000 & 0.000 & - & & & & \\
\hline 0.002 & 0.001 & 0.004 & 0.003 & $0.004^{*}$ & 0.001 & 0.000 & 0.001 & - & & & \\
\hline 0.002 & 0.000 & 0.002 & 0.000 & 0.000 & 0.001 & 0.000 & 0.001 & 0.001 & - & & \\
\hline 0.002 & 0.000 & 0.000 & 0.005 & 0.003 & 0.001 & 0.000 & 0.000 & 0.003 & 0.002 & - & \\
\hline 0.008 & 0.001 & 0.008 & 0.001 & 0.003 & 0.000 & 0.001 & 0.001 & 0.001 & 0.003 & 0.000 & - \\
\hline 0.000 & 0.000 & 0.000 & 0.001 & 0.000 & 0.000 & 0.000 & 0.000 & 0.000 & 0.000 & 0.000 & 0.000 \\
\hline
\end{tabular}


samples within the same species, for any measure of diversity, whether we compared juvenile samples to the nearest location or to pooled adults within a region.

\section{DISCUSSION}

\section{Spatial and temporal pattern of juvenile year-classes}

The consistent large-scale, north-south, geographic pattern in juvenile species composition over 3 consecutive year-classes (2000 to 2002) and the correspondence of the species composition of juveniles to that in the overall adults (Burford 2009) indicate that new juveniles are drawn from different pools of adults in the northern region (e.g. a greater frequency of Type 1 adults at Fort Bragg). The largescale pattern provides evidence of a frequency break in the Type 1 species between the Fort Ross and Sandhill sampling locations, which coincides with the upwelling and relaxation zone north and south of the promontory at Point Reyes (Fig. 1) and a potential geographic break at the San Francisco Bay inlet. Wing et al. (1995a) found differences in upwelling and relaxation events around Point Reyes that affected settlement patterns of crabs (predominately Cancer spp.), with lower and episodic settlement in the north and higher frequency settlement to the south of this barrier. This suggests that the samples in this study, on average, reflect a distribution break in the 2 cryptic species somewhere between the Point Reyes region and northern Monterey Bay. This break was indicated by a severe drop in number, particularly in the 2002 year-class, but was not a hard break due to the few Type 1 juveniles found in the central and southern regions. Similar to the broader geographic patterns, species composition differences also drove the smaller spatial and temporal scale genetic patchiness within all regions. For example, at individual sample locations in the 2002 year-class, we found spatial differences in the species composition of juveniles in the northern and central regions. We also found temporal variation between sampling years in the number of Type 1 juveniles at sample locations that were sampled in multiple years throughout all regions, with a higher frequency of Type 1 species in the 2002 year-class than in previous year-classes. Unlike previous studies on other species that showed northern dispersal limitation across the proposed biogeographic barrier at Point Conception (e.g. Balanus glandula, Wares et al. 2001), we did not find significant genetic structure within juveniles of either species across this region, only genetic patchiness within the central region in the Type 2 species. Therefore, while the major pattern of genetic variation in juveniles was the north-south difference in the frequency of the 2 species, there was also variation within regions.

While we found both small-scale and large-scale geographic patterns of species composition, the genetic structure within each species was largely uniform, with the exception of small-scale genetic differences within the Type 2 species. The lack of largescale genetic structure in the juveniles of each species, or for that matter in the adults (Burford 2009), demonstrates that an extended pelagic phase facilitates extensive gene flow and maintains genetic homogeneity over large geographic distances. Although this pattern appears to be consistent, we also found significant small-scale genetic structure within the Type 2 juveniles in the central region in both year-classes, similar to previous studies of juvenile Sebastes mystinus (Burford \& Larson 2007) and marine invertebrates (e.g. Moberg \& Burton 2000) in this region. This low level of genetic structure of Type 2 juveniles was similar to the small-scale genetic structure of the Type 2 adults south of the Monterey region (Burford 2009). Therefore, while the geographic pattern may vary between juveniles and adults, small-scale genetic structure within the Type 2 species is a consistent feature. In contrast, genetic connectivity over large geographic regions was a consistent feature of the Type 1 species. Given the similar life history, these 2 recent species have different spatial patterns of genetic structure, with the northerly-distributed species (Type 1) displaying genetic homogeneity among adult and juvenile samples and the southerly-distributed species (Type 2) displaying low levels of genetic structure among adult and juvenile samples.

While we found small-scale and low levels of genetic structure within the Type 2 species similar to the previous study of Sebastes mystinus (Burford \& Larson 2007) and studies of sea urchin species (Edmands et al. 1996, Moberg \& Burton 2000, Flowers et al. 2002), we did not find lower genetic diversity in juvenile samples compared to the nearest or the pooled adult sample. Previous studies on genetic structure of sea urchins found evidence of genetic patchiness without the requisite decrease of genetic diversity indicative of sweepstakes recruitment (e.g. Flowers et al. 2002). Although we had adequate statistical power to detect changes in genetic diversity supportive of sweepstakes recruitment, the lack of 
strong evidence for this mechanism within the Type 2 species points to other factors that may contribute to this pattern, including dispersal limitations within the Monterey Bay region. As hypothesized by Burford \& Larson (2007), sweepstakes recruitment may be temporally variable, present in some years perhaps due to lower or moderate year-class sizes, such as the 2000 year-class, and not in others, such as the following larger year-classes of 2001 and 2002. This may be a characteristic of species with multiple generations and long pelagic phases where different year-classes are likely subjected to different mechanisms (e.g. different reproductive success or dispersal trajectories). If this is true, then 'strong' yearclasses may have higher effective population sizes and temper any variation produced by sweepstakes recruitment in previous 'weak' year-classes of lower effective population size. While individual yearclasses may or may not exhibit this type of genetic structure, it is unclear whether this subtle genetic variation has far reaching effects on the adult population that is comprised of many individual yearclasses. Given harvesting practices that remove the larger, older adults and change the reproductive adult composition from many to just a few or one year-class (e.g. Santa Cruz Island), the temporal variation we found in this study may cause interannual changes in the genetic structure of the adult population and may become a consistent feature. S. mystinus has suffered precipitous declines in the Type 2 species range, particularly in the southern California bight (Stephens et al. 1994, Love et al. 1998, Love et al. 2002). If the age structure of adult $S$. mystinus is further truncated, we would predict a lowering of overall genetic diversity and effective population size of the Type 2 species.

\section{Spatial and temporal pattern between adults and juveniles}

In this study we found a general pattern, to a varying degree, of a higher number of Type 1 individuals in the juveniles than the adults. The 2 competing hypotheses, that juveniles were either a reflection of the local adult composition or not, had different levels of support depending on the sampling location and time between collections of juveniles and adults. In particular, there were large differences in species composition between adults and juvenile yearclasses at 2 locations in the northern region (Ocean Cove and Fort Ross) and smaller differences at Fort Bragg, Monterey and Gaviota. While, in general, this pattern was more pervasive between adults and the 2002 year-class, in some cases the discrepancy was consistent over 3 consecutive year-classes (Fig. 1). Therefore, the juvenile samples at these locations in the northern region largely support the hypothesis that juveniles do not reflect the species composition of the local adults, whereas other juvenile samples in the central and southern regions, which were dominated by Type 2 adults, were largely similar to regional adults with a few exceptions

There are several potential explanations, that may or may not be mutually exclusive, for the discrepancy in species composition between the juveniles and adults in the northern region and at only a few sampling locations in the central and southern regions. These include sources of Type 1 adults that were not sampled (e.g. deeper depth than the nearshore region, small patches or habitat partitioning), longdistance dispersal from Type 1 adult sources in the Fort Bragg area or further north, or a series of years where conditions favored recruitment of Type 1 juveniles (temporally variable local adaptation). The mechanisms that support these 3 explanations include (1) an ontogenetic shift of juveniles from the settlement locations to an unknown, distinct Type 1 adult habitat or depth, (2) a change in conditions that allowed increased recruitment of Type 1 juveniles from other sources during the study period (in contrast to years that produced the adult population), or (3) selection against Type 1 juveniles at sampling locations where there were discrepancies (e.g. Ocean Cove and Fort Ross). An ontogenetic shift would suggest a population of unsampled Type 1 adults and would predict more regular recruitment of Type 1 juveniles to nearshore habitats in the northern region or throughout the range, which was not supported by our data. Therefore, the first mechanism does not seem as likely as the second and third mechanisms. Due to the commensurate collections of adults at Ocean Cove and Fort Ross in 2002, we could not confirm whether individuals from both species reached the reproductive adult stage. Therefore, we cannot conclusively exclude the third mechanism at these 2 locations. However, the sample of adults at Fort Bragg in 2006 were likely comprised of the 2000, 2001 and 2002 year-classes, which supports Type 1 juveniles in 2002 reaching reproductive age at this location and would further exclude an ontogenetic shift and selection against Type 1 juveniles (Mechanisms 1 and 3) at this location. The finding of equal frequencies of Type 1 adults at Fort Bragg (Burford 2009) also shows a change from the previous adult sample in this region (Burford \& Larson 2007), further support- 
ing a recent change in species composition at this location. Therefore, the evidence from Fort Bragg, combined with the increase in frequency of Type 1 juveniles in the 3 consecutive year-classes, suggests temporal differences between the adults born 5 yrs or more before the juveniles and further supports a recent change in species composition in this region. Whereas our data supports the spatial increase of Type 1 individuals over time, which suggests passive flow from regions where Type 1 dominates to regions where it does not, we need to reconcile the recent increase in frequency of Type 1 individuals compared to the previous several decades.

The juvenile year-classes from the 2 years of this study and the previous one (2000 to 2002) were born, on average, in relatively colder years (from January to July - pelagic and settlement period; Murphree et al. 2003) (Fig. 3) and relatively stronger year-classes (Mills et al. 2007) than in years that the adults sampled in this study were born. These, on average, colder years may constitute a shift to a cold-regime in the California Current (Peterson \& Schwing 2003) as part of the periodic changes in the ocean climate throughout the range of Sebastes mystinus (Pacific Decadal Oscillations, PDO; Murphree et al. 2003). An association between cold years and higher abundances of pelagic juveniles, or 'strong' year-classes, was observed in previous studies (Mills et al. 2007). Both 2001 and especially 2002 had higher abundances of juveniles in the California Current System (Miller \& Sydeman 2004, Mills et al. 2007, Caselle et al. 2010), higher abundance of $S$. mystinus in the central coast (M. Carr unpubl. data), and also higher

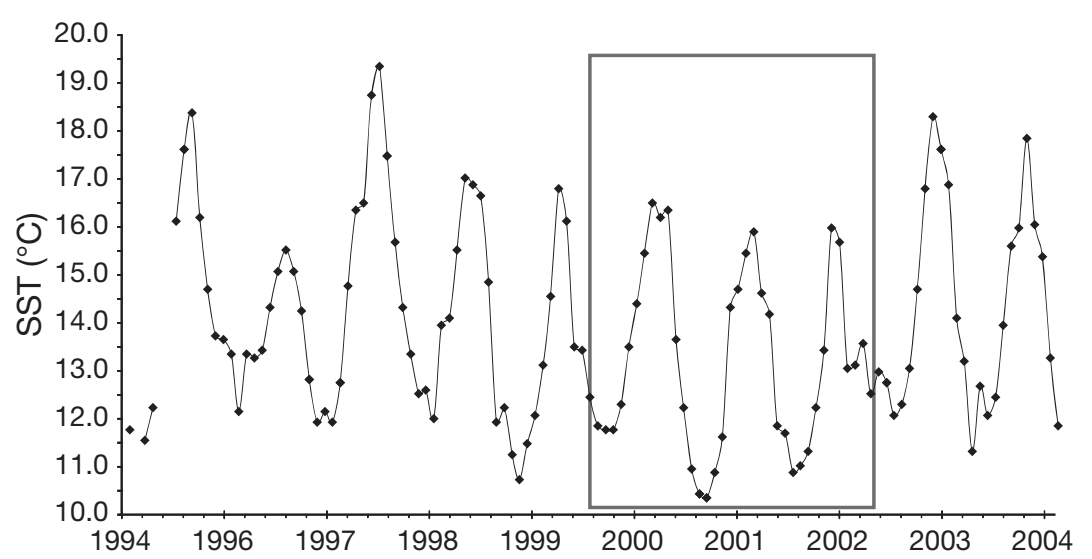

Fig. 3. Sea surface temperature (SST) in California, USA. The boxed region highlights the 3 years that correspond to the 3 year-classes analyzed in this study $(2000,2001$, and 2002). These data are from the NOAA Coast Watch Program, NOAA NESDIS Office of Satellite Data Processing and Distribution, and NASA's Goddard Space Flight Center, Ocean Color Web abundances in the northern region ( $\mathrm{T}$. Laidi pers. comm.) than previous years. In contrast, the adults sampled in 2002 or earlier at Fort Ross and Ocean Cove and throughout the central and southern locations were born during a warmer regime with different recruitment conditions and strength (Murphree et al. 2003) (Fig. 3). While it is possible that larger year-classes increased the probability of southward long-distance dispersal of larvae from the northern regions where the Type 1 adults dominate, there was also a relatively large year-class in 1991 and also in 1986 and 1987, and the adults that represent these year-classes were predominately Type 2 individuals (Burford 2009). The pattern could also be explained by better survival of Type 1 individuals during the cold-regime. However, individuals born in colder than the long-term average years in the past (1978 and 1991) (Fig. 3) were also present in the adult samples (Gundelfinger 2005, Burford 2009), and again these adults were predominately Type 2 individuals. Therefore, it is unlikely that one mechanism, large year-classes vs. ocean-climate differences, explains the change in frequency of the Type 1 species that we observed in this study. The occurrence of Type 1 juveniles south of the area where Type 1 adults dominate (Oregon and Washington) was likely the result of long-distance dispersal under favorable oceanographic conditions (colder regime). The result is a southward expansion of the Type 1 species into California.

Ideally, a second set of samples would identify whether Type 1 juveniles reached adulthood, confirming a trend rather than an anomaly. However, juveniles would be the first to show signs of an increase in the Type 1 species in California. If these juveniles reach reproductive age, we would predict greater numbers of Type 1 adults in the northern region. We would also predict that in years that promote high dispersal, a greater number of Type 1 individuals would be found in the central and southern regions as dispersing larvae penetrate dispersal barriers north of the Monterey Bay region. How these individuals would fare with warmer years is unclear, and collections of new year-classes in these years would test our hypothesis that Type 1 individuals are, in part, adapted to colder regions. The long pelagic phase and the high, realized dispersal found in 
the genetic analysis within species would predict a rapid spread or increase in the Type 1 species. Any selective forces that affect the recruitment of Type 1 juveniles, depending on their strength, may reduce this rate. Whereas an expansion of the Type 1 species southward in colder years fits the pattern indicated by our data, an analysis of the frequency of both species in warmer oceanographic regimes in this region would test this inference.

In conclusion, the theoretical prediction that longer pelagic duration should maintain genetic homogeneity over large geographic distances was largely true for both species of Sebastes mystinus, with the exception of low-level but significant genetic structure within the Type 2 species. The low-level genetic structure may reduce the effective population size and be important for management considerations if the adult Type 2 populations are further fished down to just a few year-classes. We found a temporal difference in species composition, both between the 2 yearclasses and between juveniles and adults, which suggests a recent change in frequency of the Type 1 species in California. The recent change in the northern region provides evidence of a recent range expansion of the Type 1 species from regions where it dominated (Washington and Oregon) into the California region. If it is true that the colder regimes facilitate increased survival and reproduction of the Type 1 individuals, then there should be a similar decrease in the settlement or survival of Type 1 juveniles in following warmer years. For management purposes, the frequency of the 2 reproductively isolated groups of S. mystinus need to be accounted for throughout this region to facilitate conservation for this species. In addition, when juveniles of both species are indistinguishable from each other, predictions on year-class strength based on juvenile surveys or pelagic juvenile sampling may severely overestimate the population size. Overall, the geographic pattern of species composition of $S$. mystinus juveniles and adults in California involves both long-distance dispersal and changes in oceanographic conditions.

Acknowledgements: We thank the following for their assistance with collections: R. Buckley, D. Bondemiller, K. Gordon, J. Headlee, D. VenTresca, P. Gundelfinger, R. Larson, T. Laidig, S. Parker, A. Chapelle, J. Barlow, M. O'Farrell, P. Tompkins, J. Fugurski, J. Grover, R. Nakamura, T. Olive, J. Hyde, M. Ramon, N. Crane, M. McCrea, J. Barr, the Oregon and Washington Department of Fish and Wildlife and the California Department of Fish and Game. We also thank M. Reiskind, R. Larson, S. Palumbi, P. Raimondi and 3 anonymous reviewers for comments that improved the manuscript. The project was generously funded by grants to M.O.B. from the PADI Foundation, Myers Trust Grant, The ASIH Raney Fund, Friends of the Long Marine Lab Fellowship, California Environmental Quality Initiative (CEQI) Graduate Fellowship, the Marilyn C. Davis Grant, and from the Packard Foundation's Partnership for the Interdisciplinary Study of Coastal Oceans (PISCO). This is contribution 407 from PISCO, funded primarily by the Gordon and Betty Moore Foundation and the David and Lucile Packard Foundation.

\section{LITERATURE CITED}

Ammann AJ (2004) SMURFs: standard monitoring units for the recruitment of temperate reef fishes. J Exp Mar Biol Ecol 299:135-154

Anderson TW, Carr MH (1998) BINCKE: a highly efficient net for collecting reef fishes. Environ Biol Fishes 51:111-115

> Buonaccorsi VP, Kimbrell CA, Lynn EA, Vetter RD (2002) Population structure of copper rockfish (Sebastes caurinus) reflects postglacial colonization and contemporary patterns of larval dispersal. Can J Fish Aquat Sci 59: 1374-1384

Buonaccorsi VP, Westerman M, Stannard J, Kimbrell C, Lynn E, Vetter RD (2004) Molecular genetic structure suggests limited larval dispersal in grass rockfish, Sebastes rastrelliger. Mar Biol 145:779-788

Burford MO (2009) Demographic history, geographic distribution and reproductive isolation of distinct lineages of blue rockfish (Sebastes mystinus), a marine fish with a high dispersal potential. J Evol Biol 22:1471-1486

Burford MO, Bernardi G (2008) Incipient speciation within a subgenus of rockfish (Sebastosomus) provides evidence of recent radiations within an ancient species flock. Mar Biol 154:701-717

Burford MO, Larson RJ (2007) Genetic heterogeneity in a single year-class from a panmictic population of adult blue rockfish (Sebastes mystinus). Mar Biol 151:451-465

Burford MO, Bernardi G, Carr MH (2011) Analysis of individual year-classes of a marine fish reveals little evidence of first generation hybrids between cryptic species in sympatric regions. Mar Biol 158:1815-1827

Caselle JE, Carr MH, Malone D, Wilson JR, Wendt DE (2010) Can we predict interannual and regional variation in delivery of pelagic juveniles to nearshore populations of rockfishes (genus Sebastes) using simple proxies of ocean conditions? Cal Coop Ocean Fish Invest Rep 51: 91-105

Cowen RK, Sponaugle S (2009) Larval dispersal and marine population connectivity. Annu Rev Mar Sci 1:443-466

Cowen RK, Gawarkiewicz G, Pineda J, Thorrold SR, Werner FE (2007) Connectivity in marine systems: an overview. Oceanography 20:14-21

Edmands S, Moberg PE, Burton RS (1996) Allozyme and mitochondrial DNA evidence of population subdivision in the purple sea urchin Strongylocentrotus purpuratus. Mar Biol 126:443-450

Evanno G, Regnaut S, Goudet J (2005) Detecting the number of clusters of individuals using the software STRUCTURE: a simulation study. Mol Ecol 14:2611-2620

> Falush D, Stephens M, Pritchard JK (2003) Inference of population structure using multilocus genotype data: linked loci and correlated allele frequencies. Genetics 164: 1567-1587

Flowers JM, Schroeter SC, Burton RS (2002) The recruitment sweepstakes has many winners: genetic evidence from the sea urchin Strongylocentrotus purpuratus. Evolution 56:1445-1453 
Goudet J (1995) FSTAT (Version 1.2): a computer program to calculate F-statistics. J Hered 86:485-486

Goudet J (1999) PCA-GEN for Windows. University of Lausanne, Lausanne

Gundelfinger P (2005) Regional variation in year-class structure of blue rockfish (Sebastes mystinus). Master's thesis, San Francisco State University, San Francisco, CA

Guo SW, Thompson EA (1992) Performing the exact test of Hardy-Weinberg proportion for multiple alleles. Biometrics 48:361-372

Hedgecock D, Hutchinson ES, Li G, Sly FL, Nelson K (1994) The central stock of northern anchovy (Engraulis mordax) is not a randomly mating population. Cal Coop Ocean Fish Invest Rep 35:121-136

Hess JE, Vetter RD, Moran P (2011) A steep genetic cline in yellowtail rockfish, Sebastes flavidus, suggests regional isolation across the Cape Mendocino faunal break. Can J Fish Aquat Sci 68:89-104

Hyde JR, Vetter RD (2007) The origin, evolution, and diversification of rockfishes of the genus Sebastes (Cuvier). Mol Phylogenet Evol 44:790-811

Hyde JR, Kimbrell CA, Burdick JE, Lynn EA, Vetter RD (2008) Cryptic speciation in the vermilion rockfish (Sebastes miniatus) and the role of bathymetry in the speciation process. Mol Ecol 17:1122-1136

Laroche WA, Richardson SL (1981) Development of larvae and juveniles of the rockfishes Sebastes entomelas and $S$. zacentrus (family Scorpaenidae) and occurrence off Oregon, with notes on head spines of $S$. mystinus, S. flavidus, and $S$. melanops. Fish Bull 79:215-230

Larson RJ, Lenarz WH, Ralston S (1994) The distribution of pelagic juvenile rockfish of the genus Sebastes in the upwelling region off central California. Cal Coop Ocean Fish Invest Rep 35:175-221

Love MS, Caselle JE, Herbinson K (1998) Decline in nearshore rockfish recruitment and populations in the southern California Bight as measured by impingement rates in coastal electrical power generating stations. Fish Bull 96:492-501

Love MS, Yoklavich M, Thorsteinson L (2002) The rockfishes of the northeast Pacific. University of California Press, Berkeley, CA

Miller DJ, Lea RN (1972) Guide to coastal marine fishes of California. Calif Dep Fish Game Fish Bull 157:1-235

Miller AK, Sydeman WJ (2004) Rockfish response to low-frequency ocean climate change as revealed by the diet of a marine bird over multiple time scales. Mar Ecol Prog Ser 281:207-216

Miller JA, Banks MA, Gomez-Uchida D, Shanks AL (2005) A comparison of population structure in black rockfish (Sebastes melanops) as determined with otolith microchemistry and microsatellite DNA. Can J Fish Aquat Sci 62:2189-2198

Mills KL, Laidig T, Ralston S, Sydeman WJ (2007) Diets of top predators indicate pelagic juvenile rockfish (Sebastes spp.) abundance in the California Current System. Fish Oceanogr 16:273-283

Moberg PE, Burton RS (2000) Genetic heterogeneity among adult and recruit red sea urchins, Strongylocentrotus franciscanus. Mar Biol 136:773-784

Murphree T, Bograd SJ, Schwing FB, Ford B (2003) Large scale atmosphere-ocean anomalies in the northeast
Pacific during 2002. Geophys Res Lett 30:8026

Nei M (1987) Molecular evolutionary genetics. Columbia University Press, New York, NY

> Palumbi SR (2003) Population genetics, demographic connectivity, and the design of marine reserves. Ecol Appl 13:S146-S158

> Peterson WT, Schwing FB (2003) A new climate regime in the northeast pacific ecosystems. Geophys Res Lett 30: 1896

Pritchard JK, Stephens M, Donnelly P (2000) Inference of population structure using multilocus genotype data. Genetics 155:945-959

Raymond M, Rousset F (1995a) Genepop (Version 1.2). Population-genetics software for exact tests and ecumenicism. J Hered 86:248-249

Raymond M, Rousset F (1995b) An exact test for population differentiation. Evolution 49:1280-1283

> Rice W (1989) Analyzing tables of statistical tests. Evolution 43:223-225

Roughgarden J, Pennington JT, Stoner D, Alexander S, Miller K (1991) Collisions of upwelling fronts with the intertidal zone: the cause of recruitment pulses in barnacle populations of central California. Acta Oecol Int J Ecol 12:35-51

> Ruzzante DE, Taggart CT, Cook D, Goddard SV (1997) Genetic differentiation between inshore and offshore Atlantic cod (Gadus morhua) off Newfoundland: a test and evidence of temporal stability. Can J Fish Aquat Sci 54:2700-2708

Selkoe KA, Henzler CM, Gaines SD (2008) Seascape genetics and the spatial ecology of marine populations. Fish Fish 9:363-377

Sivasundar A, Palumbi SR (2010) Life history, ecology and the biogeography of strong genetic breaks among 15 species of Pacific rockfish, Sebastes. Mar Biol 157:1433-1452

Sokal RR, Rohlf FJ (1995) Biometry. W.H. Freeman and Co., New York, NY

Stephens JS Jr, Morris PA, Pondella DJ, Loonce TA, Jordan GA (1994) Overview of the dynamics of an urban artificial reef fish assemblage at King Harbor, USA, 19741991: a recruitment driven system. Bull Mar Sci 55: 1224-1239

> Waples RS (1987) A multispecies approach to the analysis of gene flow in marine shore fishes. Evolution 41:385-400

> Wares JP, Gaines SD, Cunningham CW (2001) A comparative study of asymmetric migration events across a marine biogeographic boundary. Evolution 55:295-306

- Weir BS, Cockerham CC (1984) Estimating F-Statistics for the analysis of population-structure. Evolution 38: 1358-1370

Westerman ME, Buonaccorsi VP, Stannard JA, Galver L and others (2005) Cloning and characterization of novel microsatellite DNA markers for the grass rockfish, Sebastes rastrelliger, and cross-species amplification in 10 related Sebastes spp. Mol Ecol Notes 5:74-76

> Wing SR, Botsford LW, Largier JL, Morgan LE (1995a) Spatial structure of relaxation events and crab settlement in the northern California upwelling system. Mar Ecol Prog Ser 128:199-211

> Wing SR, Largier JL, Botsford LW, Quinn JF (1995b) Settlement and transport of benthic invertebrates in an intermittent upwelling region. Limnol Oceanogr 40:316-329 
Appendix 1. Sebastes mystinus. Sample locations of adults, summarized from Burford 2009. We use these locations in California for comparison to the juvenile samples. This table includes the sample location, number of collections at that location, $\mathrm{N}$, collection month, year, and method. There was no significant genetic divergence between collections within a sampling location

\begin{tabular}{|lcccccc|}
\hline Location & No. of collections & $\mathrm{N}$ & Date & Year & Collection method & Within-site divergence \\
\hline Ft. Bragg & 3 & 69 & Aug/Sep & 2006 & Port Samples & $\mathrm{p}>0.05$ \\
Ocean Cove & 2 & 41 & Sep/Oct & 2002 & CENCAL / Spear & $\mathrm{p}>0.05$ \\
Ft. Ross & 3 & 71 & Sep/Oct & 2002 & Hook\&Line & $\mathrm{p}>0.05$ \\
Monterey & 4 & 52 & May/Aug & $2003 / 04$ & Spear / Hook\&Line & $\mathrm{p}>0.05$ \\
Carmel & 3 & 93 & Feb/Jul & 2002 & CENCAL / Hook\&Line & $\mathrm{p}>0.05$ \\
Pt. Sur & 2 & 55 & Feb & $2002 / 03$ & Hook\&Line & $\mathrm{p}>0.05$ \\
Big Creek & 2 & 78 & Jul/Aug & $2002 / 03$ & Hook\&Line & $\mathrm{p}>0.05$ \\
Gaviota & 1 & 60 & Oct & 2004 & Hook\&Line & $\mathrm{p}>0.05$ \\
Santa Cruz Is. & 1 & 15 & Sep & 2002 & Hook\&Line & $\mathrm{p}>0.05$ \\
\hline
\end{tabular}

Appendix 2. Results of parameter estimates in the STRUCTURE assignment model using groupings $(K)$ of 1 to 5 , average $\log$-likelihood, variance, data estimates for $K$, and estimates of $K$. These numbers were generated using 5 runs of the admixture model in STRUCTURE

\begin{tabular}{|llrrr|}
\hline $\begin{array}{l}\text { Grouping } \\
\text { priors }\end{array}$ & Average & Variance & $\begin{array}{c}K \text { data } \\
\text { estimate }\end{array}$ & $K$ \\
\hline K1 & -84045.10 & 0.01 & 0.000 & \\
K2 & -77442.66 & 11.13 & 0.000 & 1904.62 \\
K3 & -77195.20 & 457.73 & 0.602 & 13.48 \\
K4 & -77236.08 & 1729.31 & 0.400 & 6.34 \\
K5 & -77540.46 & 9091.03 & 0.000 & \\
\hline
\end{tabular}

Appendix 3. Sebastes mystinus. Standard error of the combined 5 runs of STRUCTURE analysis of juveniles

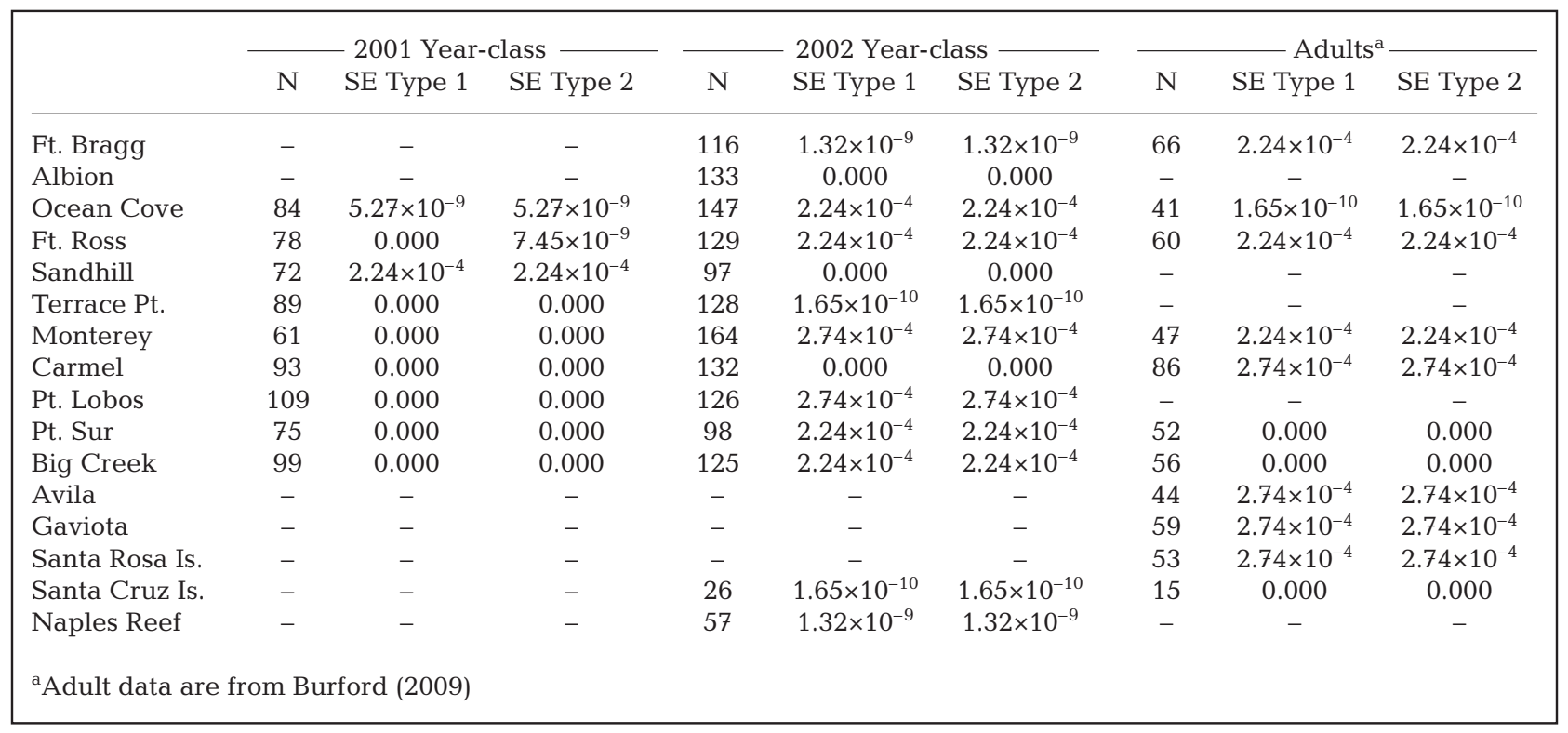

